Title of Manuscript: $\quad$ Speeding by young novice drivers: What can personal characteristics and psychosocial theory add to our understanding?

Authors:

Bridie Scott-Parker ${ }^{1,3}$

Melissa Hyde ${ }^{2,3}$

Barry Watson ${ }^{1,3}$

Mark J King 1,3

${ }^{1}$ Centre for Accident Research and Road Safety - Queensland, Queensland University of Technology, K Block, 130 Victoria Park Road, Kelvin Grove, Queensland, 4059, Australia.

${ }^{2}$ School of Psychology and Counselling, O Block B Wing, Queensland University of Technology, Kelvin Grove, Queensland, 4059, Australia.

${ }^{3}$ Institute of Health and Biomedical Innovation (IHBI), Queensland University of Technology, Kelvin Grove, Queensland, 4059, Australia.

Corresponding Author: Mrs Bridie Scott-Parker Address: $\quad$ Centre for Accident Research and Road Safety - Queensland Queensland University of Technology (QUT)

130 Victoria Park Road

Kelvin Grove

Queensland 4059

Australia.

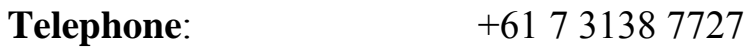

Fax: $\quad+61731380111$

Email: $\quad$ b.scott-parker@qut.edu.au 


\title{
Speeding by young novice drivers: What can personal characteristics and psychosocial theory add to our understanding?
}

\author{
B. Scott-Parker, M. K. Hyde, B. Watson, \& M. J. King
}

\begin{abstract}
Purpose: Young novice drivers continue to be overrepresented in fatalities and injuries arising from crashes even with the introduction of countermeasures such as graduated driver licensing (GDL). Enhancing countermeasures requires a better understanding of the variables influencing risky driving. One of the most common risky behaviours performed by drivers of all ages is speeding, which is particularly risky for young novice drivers who, due to their driving inexperience, have difficulty in identifying and responding appropriately to road hazards. Psychosocial theory can improve our understanding of contributors to speeding, thereby informing countermeasure development and evaluation. This paper reports an application of Akers' social learning theory (SLT), augmented by Gerrard and Gibbons' prototype/willingness model (PWM), in addition to personal characteristics of age, gender, car ownership, and psychological traits/states of anxiety, depression, sensation seeking propensity and reward sensitivity, to examine the influences on self-reported speeding of young novice drivers with a Provisional (intermediate) licence in Queensland, Australia. Method: Young drivers $(n=378)$ recruited in 2010 for longitudinal research completed two surveys containing the Behaviour of Young Novice Drivers Scale, and reported their attitudes and behaviours as pre-Licence/Learner (Survey 1) and Provisional (Survey 2) drivers and their sociodemographic characteristics.

Results: An Akers' measurement model was created. Hierarchical multiple regressions revealed that (1) personal characteristics (PC) explained 20.3\%; (2) the combination of PC and SLT explained 41.1\%; and (3) the combination of PC, SLT and PWM explained 53.7\% of variance in self-reported speeding. Whilst there appeared to be considerable shared
\end{abstract}


variance, the significant predictors in the final model included gender, car ownership, reward sensitivity, depression, personal attitudes, and Learner speeding.

Conclusions: These results highlight the capacity for psychosocial theory to improve our understanding of speeding by young novice drivers, revealing relationships between previous behaviour, attitudes, psychosocial characteristics and speeding. The findings suggest multifaceted countermeasures should target the risky behaviour of Learners, and Learner supervisors should be encouraged to monitor their Learners' driving speed. Novice drivers should be discouraged from developing risky attitudes towards speeding.

\section{Keywords}

Young driver, novice driver, speeding, social learning theory, prototype/willingness model 


\section{Introduction}

\subsection{The young novice driver}

Young drivers - drivers aged 25 years or less - are frequently novices who are new to the driving experience. Although fatality rates for young drivers in Australia have reduced in recent years (declining from $28.0 \%$ to $26.2 \%$ of driver deaths between 2001 and 2010;

DITRDLG, 2011), young people continue to be overrepresented in road crashes. Graduated driver licensing (GDL) programs are an effective intervention characterised by multiple stages of licensure, allowing novices to gain driving experience in less risky circumstances over an extended period. A modified GDL program was introduced in Queensland, Australia in July 2007 with requirements including 100 hours of logbook-certified practice and passenger restrictions in the Provisional 1 period ${ }^{1}$ (Queensland Transport, 2007). The Learner stage has been found to be the safest period of driving for the young novice and the Provisional (intermediate) period the least safe. For instance, in $2010,5.7 \%$ of the licensed Queensland driving population held a Learner licence, and represented 1.0\% of drivers involved in fatal crashes. In contrast, Provisional drivers represented 5.3\% of the licensed driving population and 8.6\% of drivers involved in fatal crashes (DTMR, 2011b).

Speeding is arguably the most widespread risky - and illegal - behaviour for drivers in general, and for young novice drivers in particular, and can become an habitual behaviour with past speeding predicting subsequent speeding (De Pelsmacker and Janssens, 2007). Speeding contributed to $22.1 \%$ of all fatalities in Queensland in 2010 (DTMR, 2011b) and to $30.2 \%$ of young driver and rider fatalities in Queensland in the five years to 31 December 2010 (DTMR, 2011a). In a study undertaken in Victoria, Australia, young males reported driving more than $10 \mathrm{~km} / \mathrm{hr}$ over the speed limit on half of their recent journeys (Vassallo et al. 2007). Speeding is of particular concern for young novice drivers due to their inexperience in detecting and responding appropriately to driving hazards. 
Typically research into risky driver behaviour, including speeding, considers sources of influence on behaviour in isolation; for example, examining only the influence of the personal characteristics of the young novice driver, their previous behaviour, or constructs from psychosocial theory. It is fundamental, however, that road safety researchers acknowledge that a variety of factors may simultaneously influence the behaviour of the young novice driver; therefore holistic approaches which incorporate personal characteristics, social, and non-social influences need to be operationalised in attempts to understand risky behaviours such as speeding.

\subsection{The personal characteristics of the young novice driver}

Personal characteristics such as driver gender $(80.9 \%$ of $17-24$ year old drivers killed in Queensland in 2010 were male; DTMR, 2011a) and age (youngest drivers account for the greatest proportion of speed-related crashes at all licence levels; Lam, 2003) are associated with increased young driver crash risk. Car ownership (e.g., Scott-Parker et al. 2011a; Williams et al. 2006) or vehicle access (e.g., Cammisa et al. 1999; Garcia-Espana et al. 2009) are also associated with risky driving including speeding. An increased likelihood of risky driving, such as speeding, has been found also for novices reporting psychological distress (anxiety/depression, Scott-Parker et al. 2011b; Sumer, 2003) and greater reward sensitivity (Scott-Parker et al. online). Sensation seeking propensity is also associated with risky driving (Jonah, 1997), including self-reported (Sumer, 2003) and actual speeding (Greaves and Ellison, 2011), for male and female young novice drivers alike (Scott-Parker et al. online, under review a). To further our understanding of these influences, investigations into selfreported speeding of young novice drivers should be guided by a psychosocial theoretical framework, such as Akers' social learning theory (SLT), which has the capacity to incorporate personal characteristics (e.g., sensation seeking propensity, reward sensitivity) 
while simultaneously considering social and non-social influences including attitudes and reinforcement.

\subsection{Akers' social learning theory (SLT) and the young novice driver \\ Akers' SLT (Akers et al. 1979) emerged within the criminological domain and} focuses on the social and non-social conditioning influences in the initiation and maintenance of delinquent behaviour. The constructs of differential association, definitions, imitation, and differential reinforcement are key in the context of the 'delinquent behaviour' of speeding by the young novice driver. Differential association represents the interactions between the young novice driver and significant others and varies according to frequency, intensity, duration and priority; definitions encompasses attitudes and orientations and includes values and rules regarding behaviours; behaviours are primarily learned through imitating significant others; whilst behaviours are maintained through differential reinforcement by significant others, comprising rewards and punishments.

The social learning process begins for the young driver when they differentially associate with their parents and friends who, as similar-aged peers, are likely to be young novice drivers. For the adolescent, differential association with parents will likely be of longer duration and greater frequency, and with peers of greater priority and intensity. The behaviours and attitudes of these models are subsequently imitated by the young novice who also develops attitudes regarding speeding. These significant persons are able to differentially reinforce speeding performed by the young novice driver through punishment and rewards. If the young novice driver has parents and/or friends who have risky attitudes towards speeding and engage in speeding, and if these significant others reward and/or do not punish young novice driver speeding, the young novice driver will likely develop and maintain risky attitudes towards speeding and to speed themselves. 
Akers' SLT has been applied in a variety of adolescent research, including cigarette smoking (Krohn et al. 1985) and illicit drug and alcohol use (Akers et al. 1979) and more recently in the road safety context including self-reported risky driving of young novices (Bates et al. 2009; Scott-Parker et al. 2009a, 2009b), unlicensed driving (Watson, 2004), and speeding (Fleiter et al. 2006, 2010). There is contention regarding the 'order' of influence of each of Akers' constructs (e.g., Krohn, 1999), compounded by a lack of model specificity (Krohn et al. 1985). The debate centres upon Akers' suggestion that differential association is the primary construct to exert influence over the risky behaviour of the adolescent (Akers et al. 1979). In addition, there is controversy regarding construct independence (e.g., Amdur, 1989), and some constructs have been difficult to measure consistently (e.g., 'imitation').

High construct inter-correlations within early SLT research (e.g., Akers et al. 1979) suggest the measurement model alleged to support the structure, and therefore the explanatory ability, of the theory is incorrect. In particular, the large proportion of variance in the risky behaviour of interest explained by just one of the four constructs (differential association) has suggested to some that there is no need to incorporate all four constructs within analyses. However, in many applications of Akers' SLT, a measurement model was not created or tested, and redundant items or items that load upon multiple constructs may not have been identified (Amdur, 1989). Accordingly, in the current study, an initial measurement model of Akers' SLT was created prior to the inclusion of the model within the remainder of the analyses. The amounts of variance explained by the constructs and their respective (sub)scales were examined also.

Qualitative research undertaken by the authors (Scott-Parker et al. under review b) framed within Akers' SLT also revealed an interesting phenomenon pertaining to young novice driver behaviour. Young novices reported that the reaction of their parents, friends, and Police - ostensibly within the differential reinforcement dimension - was contingent 
upon the outcome of the behaviour. To illustrate, young novice drivers reported friends and parents would not care if they bent ${ }^{2}$ road rules and 'nothing bad happened', therefore there would be no punitive consequences. However, if the young novice bent road rules and 'something bad happened' - such as a crash or a traffic citation - they anticipated considerable negative consequences from parents and friends. Accordingly an additional reinforcement schedule measuring this phenomenon utilising a 'probability' response format (Akers, 2009) is incorporated within the present research.

Akers' SLT explains more variance in risky driving behaviour when compared to other theories such as deterrence theory (e.g., Fleiter et al. 2006) and captures constructs incorporated within other theories such as social identity theory (Scott-Parker et al. 2009a). Akers' SLT can be augmented also by elements of other psychosocial theories (Elliott and Thomson, 2010; Horvath et al. 2012). In particular, the prototype/willingness model (PWM, Gibbons and Gerrard, 1995), which considers not only the attitudes of the young adult but also prior behaviour, intentions and situational willingness as influences on risky behaviour, represents a potentially useful perspective with which to augment Akers' SLT.

\subsection{The prototype/willingness model (PWM) and the young novice driver}

The PWM proposes that young adult health risk behaviour occurs due to adolescents' openness to opportunities (a willingness) to be less safe rather than a deliberate intention to be risky (Ouellette et al. 1999). Accordingly within the context of young novice drivers speeding, a willingness to speed, particularly in the presence of peers (Gerrard et al. 2003), may be a stronger predictor of speeding than future intentions to speed. Moreover, if a young novice driver holds a favourable socially-shared image - a prototype - of a typical risky young driver, the more likely the novice is to speed if the circumstances to do so arise (Ouellette et al. 1999). Consistent with SLT, attitudes held by the young driver towards following road rules are also pivotal, as are subjective norms (i.e., perceptions of what others 
think and do) of parents and friends. The PWM constructs are presumed to operate in a temporal and longitudinal fashion, with constructs measured at Time 1 and behaviour measured at Time 2 .

The PWM has been applied to understand a range of adolescent risky behaviour including unprotected sex (Thornton et al. 2002), smoking (Hukkelberg and Dykstra, 2009), alcohol and illicit drug use (Gibbons et al. 2004) and risky driving (Gerrard et al. 1996; Gibbons and Gerrard, 1995). Other studies have augmented successfully elements of the PWM (e.g., prototypes) within decision-making models such as the theory of planned behaviour (e.g., Hyde and White, 2010), including for an examination of young drivers' speeding intentions (Cestac et al. 2011). Accordingly the research will further augment Akers' SLT with willingness and intentions to be risky, safe and unsafe prototypes, and prior speeding, which may provide unique insight into the various influences upon speeding by young novices.

\subsection{Study aims}

The study aims were to develop and test a measurement model for Akers' SLT; and to explore the influences on speeding by young novice drivers including (1) personal characteristics (age, gender, car ownership, reward sensitivity, sensation seeking propensity, depression, anxiety), (2) SLT (differential association, imitation, definitions, differential reinforcement), and (3) PWM (Learner speeding, willingness, intentions, safe/unsafe prototypes). Separate gender analyses will be undertaken also given the reported gender differences in the experience of psychological distress (Botticello, 2009; Crawford et al. 2001), crashes (Lang et al. 1996) and speeding by young drivers (e.g., Horvath et al. 2012).

\section{Method}

\subsection{Participants}

Young novice drivers $(n=1170,709$ women $)$ aged $17-25$ years $(M=17.90, S D=$ 
1.51) volunteered to complete a 30-minute Learner Survey (“Learner drivers"). These drivers had just passed their practical driving assessment (PDA) and progressed from a Learner to a Provisional 1 (P1) driver's licence. Six months later, 378 of these drivers (265 females, $M=$ 18.22 years, $S D=1.59$ ) completed the 30-minute Provisional Survey ("Provisional drivers"). Chi-square analyses revealed participants who completed both surveys were significantly more likely to be female and to be studying.

\subsection{Materials}

Participants completed two similar surveys. The Learner Survey incorporated items exploring pre-Licence driving, attitudes and behaviours of Learners, and experiences related to obtaining a Provisional licence in Queensland's enhanced GDL program. The Provisional Survey explored the experiences, attitudes and behaviour of the same drivers who now had six months independent driving experience with a Provisional licence.

\subsubsection{Personal characteristics}

In both surveys participants reported their age and gender; and completed the binary 11-item abridged Sensitivity to Reward Questionnaire (Abridged-SRQ, Scott-Parker et al. under review a) (yes, no), the 8-item Brief Sensation Seeking Scale (BSSS, Hoyle et al. 2002) (1 strongly disagree, 5 strongly agree), and the 10-item Kessler's Psychological Distress Scale (K10, Kessler and Mroczek, 1994, cited in Andrews and Slade, 2001) (1 none of the time, 5 all of the time) divided into depression and anxiety subscales. All scores were summed. Higher scores on the Abridged-SRQ, BSSS, and K10 indicate greater reward sensitivity, sensation seeking propensity, anxiety and depression. The Provisional Survey gauged car ownership (yes, no), and analyses used Provisional Survey responses.

\subsubsection{Akers' SLT constructs}

Both surveys included multiple items to measure Akers' SLT (example items):

(a) Differential association ('My friends don't follow all the road rules all the time') 
(b) Definitions ('It is sometimes okay to bend the road rules')

(c) Imitation ('Seeing my friends bend the road rules influenced me to bend some road rules')

(d) Differential reinforcement ('My mates liked to travel with me because I bent the road

rules and made the trip more exciting')

(e) Reinforcement schedule ('Your parents would have taken your keys off you [if you bent the road rules and something bad happened like you crashed the car]')

Higher scores indicated more agreement with a construct. All analyses used the Provisional Survey responses.

\subsubsection{Gerrard and Gibbons’ prototype/willingness model constructs}

The Learner survey operationalised 6 unsafe and 6 safe prototype items (1 not at all descriptive; 7 extremely descriptive). One item measured intentions to follow road rules (1 definitely will not, 7 definitely will) and three items measured willingness-to-speed (1 very unwilling; 7 very willing). Higher scores indicate more of a construct. Analyses used Learner Survey responses.

\subsubsection{Speeding}

Both surveys contained the Behaviour of Young Novice Drivers Scale (BYNDS), a 44-item instrument with a 5-point Likert scale that measures the frequency of risky driving behaviours (1 never, 5 nearly all the time) (Scott-Parker et al. 2010). Six BYNDS items capturing the frequency and context in which speeding occurs were summed to comprise a speeding subscale (Scott-Parker et al. in press). Higher scores indicate more speeding.

\subsection{Design and procedure}

Every Learner in Queensland who progressed to a P1 licence April through June 2010 was invited to participate in a longitudinal research project exploring novice driver behaviours and attitudes. Participation incentives included the chance to win petrol vouchers and/or movie tickets. The Learner Survey response rate was $14.4 \%(n=1333$ drivers aged 
17-38 years, 9393 reminder letters were mailed to novices). The response rate for novices aged 17-25 years could not be calculated because the ages of novices who did not participate could not be determined due to Privacy restrictions. Six months later, Learner participants completed the Provisional Survey. The attrition rate for drivers aged 17-25 years between surveys was $66.9 \%$. The online survey tool was administered using KeySurvey Enterprise Online Survey Software (IBM).

\subsection{Statistical analysis}

Bivariate correlations explored the strength of association between all variables: between continuous variables utilised Pearson's product moment correlation $(r)$; between continuous and dichotomous variables utilised point biserial correlations $\left(r_{p b}\right)$; between dichotomous variables utilised the phi coefficient $(\phi)$ (Cohen, 1996). Internal consistency was measured using Cronbach's alpha ( $\alpha$ ). Exploratory factor analysis (EFA) examined the underlying structure of the safe/unsafe prototypes. Confirmatory factor analysis (CFA) was used to construct the SLT measurement model. Due to sample size restrictions (20 participants per parameter is recommended, Kline, 2011), the predictive ability of the various constructs of interest were calculated via regression. Hierarchical multiple regression (HMR) was used to control the order in which variables were entered into regression equations. A minimum HMR sample size of $n \geq 50+8 m$ (where $m=$ the number of independent variables) (Tabachnik and Fidell, 1996) is required for a preferred power of $80 \%$, and to detect a medium effect size of .20 . Unless otherwise stated sample size requirements were met. Analyses were evaluated at significance level $\alpha=.05$. Missing data were not imputed.

\section{Results}

\subsection{Personal characteristics of the sample}

\subsubsection{Descriptives}


The sample was predominantly female ( $70.1 \%$ of P1 drivers), were aged $17-18$ years (71.7\%), and owned their own car (79.9\%). The participants reported moderate levels of depression and anxiety, sensation seeking propensity and reward sensitivity (Table 1).

[Insert Table 1 here]

\subsubsection{Correlations}

Strong associations were found between anxiety and depression; and reward sensitivity and sensation seeking propensity (Table 1). Moderate association was found between gender and reward sensitivity; greater reward sensitivity reported by male drivers.

\subsection{Step 1: Akers' Social learning theory}

\subsubsection{Developing the measurement model}

The individual SLT constructs were examined separately, with the goal of creating internally consistent scales. Confirmatory factor analysis (CFA) using maximum likelihood estimation was used to ensure that the items contributing to the scales representing the constructs were sound indicators of the constructs (Kline, 2011). Good model fit was determined by a combination of the likelihood ratio chi-square statistic $\left(\chi^{2}\right.$ non-significant or less than three times the degrees of freedom), Bentler's Comparative Fit Index (CFI $\geq .95)$, the Steiger-Lind Root Mean Square Error of Approximation (RMSEA $\leq .08$ ) including 90\% confidence intervals (Kline, 2011), and Tucker-Lewis Index (TLI $\geq .95$ ). Path coefficients were also examined. Items were removed in successive iterations due to low factor loading $(<$ .30) until each model exhibited satisfactory fit. The internal consistency $(\alpha)$ of the scales measuring each construct was subsequently calculated via reliability analyses. Results are presented in Table 2 .

[Insert Table 2 here]

\subsubsection{Provisional speeding behaviour}


A CFA incorporated the six items representing the latent variables 'Learner speeding' and 'Provisional speeding'. The approach undertaken for the behaviour measures in 3.2.1 was replicated and both models exhibited good fit (Table 2).

\subsubsection{Descriptives and Correlations}

Table 1 summarises the means, standard deviations, and reliability of each of the Akers' constructs and the Provisional speeding behaviour measure. The Provisional drivers reported that they held moderately risky attitudes towards bending the road rules, expected punishment for bending road rules, associated with risky drivers such as their friends, reported some imitation of risky driving behaviour and some rewards for doing so, and reported speeding as Provisional drivers. Table 1 also reports the correlations between the Akers' subscales and with personal characteristics. All correlations were below 0.60 .

\subsubsection{Testing the measurement model}

As described in 3.2.1, a large number of parameters required testing in the overall measurement model. Due to the small sample size $(n=377)$ the sample could not be randomly divided into equal halves for development and testing of the measurement model, and the recommended minimum sample size of five measures per parameter could not be met (Kline, 2011). Accordingly the full measurement model could not be tested in a structural equation model and hierarchical multiple regression analyses were instead used to explore the 'ordering' of the constructs and the influence of each of the constructs upon the self-reported speeding by the young novice driver.

\subsubsection{Exploring the 'ordering' of Akers' SLT constructs}

Separate HMRs were performed via the following steps entering: (a) personal characteristics at step $1\left(\right.$ Adj. $\left.\mathrm{R}^{2}=.203\right)$; (b) individual SLT subscales/constructs at step 2 (one of six subscales was entered at a time; to explore definitions both personal attitudes and

risk assessment were simultaneously entered; to explore differential association both rewards 
and punishments were also simultaneously entered); and (c) remaining SLT individual subscales at step 3 (overall Adj. $\mathrm{R}^{2}=.411$ ). Accordingly the amount of variance explained by steps 2 and 3 was examined. Contrary to the assertion that differential association is the strongest predictor of risky behaviour (Adj. $\left.\mathrm{R}^{2}=.043\right)$, the subscale 'personal attitudes' explained the most variance in speeding $\left(\right.$ Adj. $\left.\mathrm{R}^{2}=.178\right)$. All constructs explained additional variance (step 3); therefore all constructs were retained for the remaining analyses.

\subsection{Step 2: Gerrard and Gibbons’ PWM}

\subsubsection{Development of the prototypes}

As part of an earlier research project, purposive sampling recruited 21 young drivers (12 females) aged $16-25$ years $(M=17.71, S D=2.15)$ with a Learner $(n=11)$ or Provisional driver's licence when they visited the food court of a major metropolitan shopping centre during the school holidays (Scott-Parker et al. under review b). They were asked what words could be used to describe the typical young novice driver, and could be words they, their parents, friends and other drivers could use. A list of 47 adjectives was generated (20 favourable, 27 unfavourable) and the six most common for each prototype were selected (safe: slow, good driver, safe, cautious, aware of dangers, sensible; unsafe: foolish, immature, irresponsible, show-off, impatient, lead-foot). An exploratory factor analysis of the 12 words with principal component extraction and varimax rotation using Kaiser normalisation was conducted using the Learner Survey responses. A two-factor prototype model was supported.

\subsubsection{Descriptives and Correlations}

Table 1 also summarises the descriptive characteristics of the PWM measures.

Participants reported some Learner speeding, greater intentions than willingness to speed, and more unsafe than safe prototypes (means for unsafe items ranged from 4.83 [lead foot] to 5.19 [show-off], means for safe items ranged from 2.65 [slow] to 3.39 [aware of dangers]). 
Correlations between items were below 0.60 with the exception of the expected negative correlation of -0.71 between safe and unsafe prototypes.

\subsection{Step 3: Exploring the influence of personal characteristics, SLT, and PWM}

Driver gender, age, reward sensitivity, sensation seeking propensity, depression, anxiety, and car ownership were entered instep 1 of the HMR. Akers' SLT constructs of differential association, personal attitudes, risk assessment, imitation, rewards, and punishment were entered in step 2. Unsafe prototype, safe prototype, willingness, intentions and Learner speeding were entered in step 3.At this final step, significant predictors in order of decreasing beta size were Learner speeding, personal attitudes, depression, reward sensitivity, gender and car ownership and explained $53.7 \%$ of variance in self-reported speeding (Table 3).

\section{[Insert Table 3 here]}

\subsubsection{Separate gender analyses}

Three-step HMRs replicating the structure of the previous analysis (section 3.4) were conducted for each gender. The final model was significant for males, $F(17,95)=11.14, p<$ .001 , and the combination of variables explained $60.6 \%$ of variance in self-reported speeding. The significant predictors in order of decreasing beta size were Learner speeding $(\beta=.217$, $\left.s r^{2}=.027\right)$, willingness to speed $\left(\beta=.183, s r^{2}=.021\right)$, rewards $\left(\beta=.233, s r^{2}=.016\right)$, and risk assessment $\left(\beta=-.141, s r^{2}=.014\right)$; however, the small sample size precludes definitive conclusions. The final model was also significant for females, $F(17,247)=15.34, p<.001$, explaining $48.0 \%$ of variance in self-reported speeding. Significant predictors for females in order of decreasing beta size were Learner speeding $\left(\beta=.379, s r^{2}=.096\right)$, personal attitudes $\left(\beta=.220, s^{2}=.027\right)$, sensation seeking propensity $\left(\beta=.130, s r^{2}=.012\right)$, car ownership $(\beta=$ $\left.-.114, s r^{2}=.012\right)$, and age $\left(\beta=-.103, s r^{2}=.010\right)$.

\section{Discussion}




\subsection{Theoretical implications}

\subsubsection{Personal characteristics}

The considerable variance explained by the combination of personal characteristics such as sensation seeking propensity, reward sensitivity and psychological distress in selfreported speeding suggests individual differences require further consideration in road safety research. Gender, car ownership, reward sensitivity and depression remained significant predictors of self-reported speeding after the inclusion of other theoretical constructs of interest. For females, younger age, having their own car, and greater sensation seeking propensity were also predictive of more self-reported speeding.

\subsubsection{Akers' SLT}

A measurement model for Akers' SLT was developed in a state-wide longitudinal sample of young novice drivers. Internally consistent subscales were developed, notwithstanding that the goodness-of-fit indices for imitation were poor. The contribution of the subscales measuring the constructs within this model revealed that, contrary to prior research (e.g., Akers et al. 1979), personal attitudes, rather than differential association, explained the most variance in speeding. Further research is required however before a model specifying the causal order of influence upon speeding is defined. Augmenting personal attitudes with risk assessment to more fully operationalise definitions only moderately increased the amount of explained variance. Furthermore, after consideration of other theoretical constructs and behaviours of interest, personal attitudes remained the only significant predictor of speeding, particularly for females. Analyses for the males, in contrast, revealed greater rewards was predictive of more self-reported speeding, whilst greater risk assessment was predictive of less self-reported speeding.

\subsection{3. $P W M$}


The augmentation of personal characteristics and Akers' SLT with elements of the PWM revealed prior behaviour - Learner speeding - was a significant predictor of Provisional speeding. Contrary to previous research prototypes and intentions were not significant predictors of speeding. For female Provisional drivers, a greater willingness to speed as a Learner driver predicted Provisional speeding.

\subsection{Practical implications}

\subsubsection{Personal characteristics}

The significant influence of depression upon speeding suggests targeted interventions may be beneficial not only for the mental health, but for improving the safety, of the young novice driver. Significant gender differences suggest interventions may need to be tailored to the gender of the young novice driver. In addition, education of young novices, parents, and other supervisors can highlight the increased risk associated with speeding for the young novice who has their own car within the first six months of independent licensure.

\subsubsection{Akers' SLT}

The significant influence of personal attitudes upon young novice driver speeding is consistent with other research (e.g., Fernandes et al. 2007), and suggests interventions should target risky attitudes. As noted earlier, speeding is arguably the most widespread risky and

illegal behaviour performed by drivers of all ages therefore broad enforcement campaigns are required. Parents are pivotal in the development of their novice driver - they act as models not only of behaviour but also attitudes to the pre-licence driver, and mothers in particular provide the most Learner driving supervision (Scott-Parker et al. 2011c). Attitudes and expectancies regarding risky behaviour have been found before the adolescent actually performs the behaviour (e.g., drinking alcohol, Dunn and Goldman, 1998), therefore education should also target the pre-driving teen. In addition, the significant predictors of Akers' SLT for males suggests that interventions targeting their speeding should consider 
decreasing the rewards and increasing the risks associated with this risky and illegal behaviour.

\subsection{3. $P W M$}

The augmentation with PWM constructs revealed the association between prior and current speeding, suggesting countermeasures should target the Learner driver, their parents, and other supervisors, highlighting the considerable risks associated with speeding in any circumstance. In addition, parents and other supervisors should be encouraged to monitor the Learner's speed compliance, punish deliberate speeding, and counsel the novice regarding pressure-to-speed from other drivers which may arise during peak-hour commuting. Countermeasures could incorporate an additional component encouraging the development of social skills to resist negative peer influences. Individual feedback after journeys can also reduce subsequent speeding behaviour (Prabhakharan and Molesworth, 2011).

\section{3. $\quad$ Strengths and limitations}

The research has a number of strengths, including two diverse young novice driver populations, one of which comprised a state-wide longitudinal sample representative of Queensland's population distribution profile $(62.2 \%$ of the participants resided in major cities and $1.6 \%$ in remote regions; $60.0 \%$ of Queensland's population resided in major cities and $2.0 \%$ in remote regions in 2006; ABS, 2010). The overall response rate for the first survey was low, but comparable to recent Australian research (Boufous et al. 2010). Substantial attrition occurred throughout the project, potentially due to $99 \%$ of Queensland being declared a natural disaster area due to flooding during the follow-up period (AAP, 2011).

It should be acknowledged that increasing the number of variables in HMR analyses increases the amount of variance explained, however only variables of theoretical interest were included and the sample sizes (excluding the moderation analysis for males) were sufficiently large to maintain the power of the analyses. Whilst Akers' SLT has been applied 
in a young novice driver population (Scott-Parker et al. 2009a, 2009b); it has not been applied to young novice drivers progressing through Queensland's current GDL program, nor has a measurement model been specified and tested. PWM elements also have not previously been applied to such a population. Data were collected via self-report, however the anonymous nature of the surveys likely ameliorated biases including impression management and underreporting of illegal activity. Self-report data also provided rich information regarding speeding behaviour at two stages of licensure that is not available through alternative sources (Police, licensing authorities).

\subsection{Future research}

Over recent years, young novice driver research is increasingly guided by theoretical frameworks. The application of SLT, including consideration of personal characteristics and elements of PWM, supports such research. In addition, different predictors are important for different risky driving (e.g., speeding, drink driving, Fernandes et al. 2007); therefore future research could apply this research approach to other risky driving behaviours such as drink driving and not wearing seatbelts, and in other driving populations. As noted earlier, SLT does not consider prior behaviour or the influence of willingness and intentions. Future research augmenting SLT with such variables may inform countermeasure development, application and evaluation. In addition, interactions between the psychosocial constructs and other variables of interest to young driver road safety - such as journey purpose and driving exposure - could be considered.

\section{Conclusions}

Young novice drivers continue to be overrepresented in road crash injury and fatality statistics. Countermeasures such as graduated driver licensing have contributed to an improvement in these statistics, however further interventions are required. Road safety researchers recently have begun to consider the psychosocial influences upon the risky 
behaviour of young novice drivers, and Akers' SLT and Gerrard and Gibbons' PWM provide suitable frameworks to examine the self-reported speeding of Provisional drivers as they progress through a GDL program. Future applications of Akers' SLT should apply a sound measurement model. The variety and extent of psychosocial influences upon the self-reported speeding of the young novice driver suggest that a multi-faceted intervention approach is required. Moreover, general and gender-specific countermeasures could be considered. 


\section{Acknowledgements}

Special thanks to the Department of Transport and Main Roads (formerly Queensland Transport) for their assistance in the recruitment of Learner drivers for the longitudinal research project. Thank you to Dr Judy Fleiter for her comments on an earlier draft of the manuscript. The first author is the recipient of a National Health and Medical Research Council Postgraduate Scholarship.

\section{References}

AAP, 2011. Queensland 99 per cent disaster-declared as flooded north faces new cyclone threat. The Courier Mail, 11 March 2011.

ABS, 2010.Australian Bureau of Statistics national regional profile: Queensland. ABS: Canberra.

Akers, R.L., 2009. A social learning theory of crime. In F. R. Scarpatti, A. L. Nielsen, and J.

M. Miller (Eds.), Crime and criminals: Contemporary and classic readings in criminology $2^{\text {nd }}$ ed. (pp. 214-225). New York: Oxford University Press.

Akers, R.L., Krohn, M.D., Lanza-Kaduce, L., Radosevich, M., 1979. Social learning and deviant behaviour: A specific test of a general learning theory. American Sociological Review 44, 636-655.

Amdur, R.L., 1989. Testing causal models of delinquency: A methodological critique.

Criminal Justice and Behavior 16, 35-62.

Andrews, G., Slade, T., 2001.Interpreting scores on the Kessler Psychological Distress Scale (K10). Australia and New Zealand Journal of Public Health 25 (6), 494-497.

Bates, L., Watson, B., King, M., 2009.Factors influencing learner driver experiences.

Canberra: Australian Transport Safety Bureau.

Botticello, A.L., 2009. A multilevel analysis of gender differences in psychological distress over time. Journal of Research on Adolescence 19 (2), 217-247. 
Boufous, S., Ivers, R., Senserrick, T., Stevenson, M., Norton, R., Williamson, A., 2010.

Accuracy of self-report of on-road crashes and traffic offences in as cohort of young drivers:

The DRIVE study. Injury Prevention 16, A79-A80.

Cammisa M.X., Williams A.F., Leaf, W.A., 1999. Vehicles driven by teenagers in four states. Journal of Safety Research 30, 25-30.

Cestac, J., Paran, F., Delhomme, P. 2011. Young drivers' sensation seeking,subjective norms, and perceived behavioral control and their roles in predicting speeding intention: How risktaking motivations evolve with gender and driving experience. Safety Science 49, 424-432. Cohen, B.H., 1996. Explaining psychological statistics. Melbourne: Brooks/Cole. Crawford, T.N., Cohen, P., Midlarsky, E., \& Brook, J.S., 2001. Internalizing symptoms in adolescents: Gender differences in vulnerability to parental distress and discord. Journal of Research on Adolescence 11 (1), 95-118.

De Pelsmacker, P., Janssens, W., 2007. The effect of norms, attitudes and habits on speeding behavior: Scale development and model building and estimation. Accident Analysis and Prevention 39, 6-15.

DITRDLG, 2011.Road deaths Australia.2010 Statistical Summary. Canberra: Department of Infrastructure, Transport, Regional Development and Local Government.

DTMR, 2011a.2010 Year in review road crash report.Road fatalities and hospitalised casualties. Brisbane: Department of Transport and Main Roads.

DTMR, 2011b. 2010 Queensland road toll in review. Queensland Government, Brisbane: Department of Transport and Main Roads.

Dunn, M.E., Goldman, M.S., 1998.Age and drinking-related differences in the memory organisation of alcohol expectancies in 3rd-, 6th-, 9th-, and 12th-grade children. Journal of Consulting and Clinical Psychology 66, 579-585. 
Elliott, M.A., Thomson, J.A., 2010. The social cognitive determinants of offending drivers' speeding behaviour. Accident Analysis and Prevention 42, 1595-1605.

Fernandes, R., Job, R.F.S., Hatfield, J., 2007. A challenge to the assumed generalisability of prediction and countermeasure for risky driving: Different factors predict different risky driving behaviours. Journal of Safety Research 38, 59-70.

Fleiter, J.J., Lennon, A.J., Watson, B., 2010. How do other people influence your driving speed? Exploring the 'who' and the 'how' of social influences on speeding from a qualitative perspective. Transportation Research Part F: Traffic Psychology \& Behaviour 13, (1), 49-62. Fleiter, J.J., Watson, B., Lennon, A., Lewis, I., 2006. Significant others, who are they? Examining normative influences on speeding. Paper presented at the Australasian Road Safety Research Policing Education Conference, Surfers Paradise, Australia.

Garcia-Espana, J.F., Ginsburg, K.R., Durbin, D.R., Elliott, M.R., Winston, F.K., 2009. Primary access to vehicles increases risky teen driving behaviors and crashes: National perspective. Paediatrics 124, 1069-1075.

Gerrard, M., Gibbons, F.X., Benthin, A.C., Hessling, R.M., 1996. A longitudinal study of the reciprocal nature of risk behaviours and cognitions in adolescents: What you do shapes what you think, and vice versa. Health Psychology 15, 344-354.

Gerrard, M., Gibbons, F.X., Gano, M.L., 2003. Adolescents' risk perceptions and behavioural willingness. Implications for intervention. In D. Romer (Ed.), Reducing adolescent risk:

Toward an integrated approach (pp. 75-81). California: Sage.

Gibbons, F.X., Gerrard, M. 1995. Predicting young adults' health risk behavior. Journal of Personality and Social Psychology 69 (3), 505-517.

Gibbons, F.X., Gerrard, M., Van de Lune, L.S., Wills, T.A., Brody, G., Conger, R.D., 2004. Context and cognitions: Environmental risk, social influence, and adolescent substance use. Personality and Social Psychology Bulletin 20, 1048-1061. 
Greaves, S.P., Ellison, A.B., 2011. Personality, risk aversion and speeding: An empirical investigation. Accident Analysis and Prevention 43, 1828-1836.

Horvath, C., Lewis, I., Watson, B., 2012. The beliefs which motivate young male and female drivers to speed: A comparison of low and high intenders. Accident Analysis and Prevention $45,334-341$.

Hoyle, R.H., Stephenson, M. T., Palmgreen, P., Lorch, E. P., Donohew, R. L., 2002. Reliability and validity of a brief measure of sensation seeking. Personality and Individual Differences 32, 401-414.

Hukkelberg, S.S., Dykstra, J.L., 2009. Using the prototype/ willingness model to predict smoking behaviour among Norwegian adolescents. Addictive Behaviors 34, 270-276. Hyde, M.K., White, K.M., 2010. Are organ donation communication decisions reasoned or reactive? A test of the utility of an augmented Theory of Planned Behaviour with the Prototype/Willingness Model. British Journal of Health Psychology 15 (2), 435-452. Jonah, B.A., 1997. Sensation seeking and risky driving: A review and synthesis of the literature. Accident Analysis and Prevention 29, 651-665.

Kline, R., 2011. Principles and practice of structural equation modelling ( $3^{\text {rd }}$ ed.). London: The Guilford Press.

Krohn, M.D., 1999. Social learning theory: The continuing development of a perspective. Theoretical Criminology 3, 462-476.

Krohn, M.D., Skinner, W.F., Massey, J.L., Akers, R.L., 1985. Social learning theory and adolescent cigarette smoking: A longitudinal study. Social Problems 32, 455-473. Lang, S.W., Waller, P.F., Shope, J.T., 1996. Adolescent driving: Characteristics associated with single-vehicle and injury crashes. Journal of Safety Research 27, 241-257. Lam, L.T., 2003. Factors associated with young drivers' car crash injury: Comparisons among learner, provisional, and full licensees. Accident Analysis and Prevention 35,913-920. 
Ouellette, J.A., Gerrard, M., Gibbons, F.X., Reis-Bergan, M., 1999. Parents, peers, \& prototypes: Antecedents of adolescent alcohol expectancies, alcohol consumption, and alcoholrelated life problems and rural youth. Psychology of Addictive Behaviours 13,183-97. Prabhakharan, P., Molesworth, B.R.C., 2011. Repairing faulty scripts to reduce speeding behaviour in young drivers. Accident Analysis and Prevention 43, 1696-1702.

Queensland Transport, 2007.Learning to drive.Retrieved 8 September 2008 from www.transport.qld.gov.au/Home/Licensing/Driver_licence/Getting_a licence/Car/Learning_to drive/. Scott-Parker, B., Bates, L., Watson, B., King, M.J., Hyde, M.K., 2011c.The impact of changes to the graduated driver licensing program in Queensland, Australia on the experiences of learner drivers. Accident Analysis and Prevention 43, 1301-1308.

Scott-Parker, B., Watson, B., King, M.J., 2009a.Understanding the influence of parents and peers upon the risky behaviour of young drivers. Transportation Research Part F 12, 470-482. Scott-Parker, B., Watson, B., King, M.J., 2009b. Exploring how parents and peers influence the behaviour of young drivers. 2009 Australasian Road Safety Research, Policing and Education Conference, 10-12 November, 2009, Sydney, New South Wales, Australia. Scott-Parker, B., Watson, B., King, M.J., 2010. The risky behaviour of young drivers: Developing a measurement tool. Proceedings of the 24th Canadian Multidisciplinary Road Safety Conference, Niagara Falls, Canada, June 6-9, 2010.

Scott-Parker, B., Watson, B., King. M.J., Hyde, M.K, 2011a. Mileage, car ownership, experience of punishment avoidance and the risky driving of young drivers. Traffic Injury Prevention 12 (6), 556-567.

Scott-Parker, B., Watson, B., King. M.J., Hyde, M.K., 2011b. The psychological distress of the young driver: A brief report. Injury Prevention 17 (4), 275-277. 
Scott-Parker, B., Watson, B., King. M.J., Hyde, M.K., online. The influence of sensitivity to reward and punishment, propensity for sensation seeking, depression and anxiety on the risky behaviour of novice drivers: A path model. British Journal of Psychology.

Scott-Parker, B., Watson, B., King. M.J., Hyde, M.K., in press. Young, inexperienced and on the road - do novice drivers comply with road rules? Transportation Research Record: Journal of the Transportation Research Board.

Scott-Parker, B., Watson, B., King, M.J., Hyde, M.K., under review a. A further exploration of sensation seeking propensity, reward sensitivity, depression, anxiety and the risky behaviour of young novice drivers in a structural equation model. Accident Analysis and Prevention.

Scott-Parker, B., Watson, B., King. M.J., Hyde, M.K., under review b. “They're lunatics on the road": Exploring the normative influences of parents, friends, and police on young novice’s risky driving decisions. Safety Science.

Sumer, N., 2003. Personality and behavioral predictors of traffic accidents: Testing a contextual mediated model. Accident Analysis and Prevention 35, 949-964.

Tabachnik, B.G., Fidell, L.S., 1996. Using multivariate statistics ( $3^{\text {rd }}$ ed.) New York: Harper Collins.

Thornton, B., Gibbons, F.X., Gerrard, M., 2002. Risk perception and prototype perception: Independent processes predicting risk behaviour. Personality and Social Psychology Bulletin 28, 986-999.

Vassallo, S., Smart, D., Sanson, A., Cockfield, S., Harris, A., McIntyre, A., et al., 2007.

Risky driving among young Australian drivers: Trends, precursors and correlates. Accident Analysis and Prevention 39, 444-458.

Watson, B., 2004. The psychosocial characteristics and on-road behaviours of unlicensed drivers. Unpublished PhD, Queensland University of Technology, Brisbane. 
Williams, A.F., Leaf, W.A., Simons-Morton, S.G., Hartos, J.L., 2006. Vehicles driven by teenagers in their first year of licensure. Traffic Injury Prevention 7 (1), 23-30. 


\section{Footnotes}

${ }^{1}$ The enhanced-GDL program in Queensland incorporates two Provisional licences. The novice driver progresses from a Learner to a Provisional 1 licence which must be held for a minimum 1-year period. After passing a hazard perception test, the novice progresses from a Provisional 1 licence to a Provisional 2 licence which must be held for a minimum 2-year period (Queensland Transport, 2007).

${ }^{2}$ Pilot research undertaken with young novice drivers (preliminary small group interviews, unpublished, which informed the research of Scott-Parker et al., 2009a) explored the perception of transgressions of road rules by young novice drivers. Young novice drivers reported that 'minor' transgressions, such as speeding by 5 kilometres per hour, illegal Uturns, and texting whilst driving were only 'bending' the road rules, whilst in contrast 'major' transgressions, such as speeding by 20 kilometres per hour and driving through a red light, were 'breaking' the road rules. Therefore to ensure that the young novice drivers in the present research responded to items regarding all transgressions of the road rules, the term 'bending the road rules' was operationalised. 


\section{Table 1}

Descriptive characteristics of and correlations between the personal measures and the constructs of Akers' social learning theory and Gerrard and Gibbons' prototype/willingness model

\begin{tabular}{|c|c|c|c|c|c|c|c|c|c|c|c|c|c|c|c|c|c|c|}
\hline \multicolumn{2}{|c|}{ Variable $^{\mathrm{d}}$ Age } & \multirow[t]{2}{*}{ Gen } & \multirow[t]{2}{*}{ Anx } & \multirow[t]{2}{*}{ Dep } & \multirow[t]{2}{*}{$\mathrm{SS}$} & \multirow[t]{2}{*}{$\mathrm{RS}$} & \multirow[t]{2}{*}{$\mathrm{DA}$} & \multirow[t]{2}{*}{$\mathrm{PA}$} & \multirow[t]{2}{*}{ RA } & \multirow[t]{2}{*}{ Imi } & \multirow[t]{2}{*}{$\mathrm{R}$} & \multirow[t]{2}{*}{$\mathrm{P}$} & \multirow[t]{2}{*}{ UP } & \multirow[t]{2}{*}{ SP } & \multirow[t]{2}{*}{ Int } & \multirow[t]{2}{*}{$\mathrm{W}$} & \multirow[t]{2}{*}{ LS } & \multirow[t]{2}{*}{ PS } \\
\hline Age & 1 & & & & & & & & & & & & & & & & & \\
\hline Gen & $.10^{\mathrm{a}}$ & 1 & & & & & & & & & & & & & & & & \\
\hline Anx & $-.14^{b}$ & $.13^{\mathrm{b}}$ & 1 & & & & & & & & & & & & & & & \\
\hline Dep & -.06 & $.10^{\mathrm{a}}$ & $.59^{\mathrm{c}}$ & 1 & & & & & & & & & & & & & & \\
\hline $\mathrm{SS}$ & $-.18^{c}$ & $-.16^{b}$ & $.15^{\mathrm{b}}$ & .08 & 1 & & & & & & & & & & & & & \\
\hline $\mathrm{RS}$ & $-.13^{b}$ & $-.21^{\mathrm{b}}$ & $.17^{\mathrm{c}}$ & $.16^{\mathrm{b}}$ & $.50^{\mathrm{c}}$ & 1 & & & & & & & & & & & & \\
\hline DA & -.04 & $-.18^{c}$ & $.10^{\mathrm{a}}$ & $.13^{\mathrm{b}}$ & $.32^{\mathrm{c}}$ & $.27^{\mathrm{c}}$ & 1 & & & & & & & & & & & \\
\hline PA & -.01 & $-.28^{c}$ & .06 & .00 & $.35^{\mathrm{c}}$ & $.32^{\mathrm{c}}$ & $.46^{\mathrm{c}}$ & 1 & & & & & & & & & & \\
\hline RA & $.14^{\mathrm{b}}$ & $.30^{\mathrm{c}}$ & .02 & .07 & $.20^{\mathrm{c}}$ & $-.18^{c}$ & $-.21^{\mathrm{c}}$ & $-.37^{\mathrm{c}}$ & 1 & & & & & & & & & \\
\hline Imi & -.06 & $-.19^{c}$ & .08 & .09 & $.20^{\mathrm{c}}$ & $.25^{\mathrm{c}}$ & $.42^{\mathrm{c}}$ & $.42^{\mathrm{c}}$ & $-.17^{\mathrm{c}}$ & 1 & & & & & & & & \\
\hline $\mathrm{R}$ & $-.09^{a}$ & $-.28^{c}$ & .04 & .04 & $-.11^{\mathrm{a}}$ & $.32^{\mathrm{c}}$ & $.49^{\mathrm{c}}$ & $.57^{\mathrm{c}}$ & $-.23^{c}$ & $.56^{\mathrm{c}}$ & 1 & & & & & & & \\
\hline $\mathrm{P}$ & .01 & $.12^{\mathrm{a}}$ & -.03 & .00 & $-.11^{\mathrm{a}}$ & $-.13^{b}$ & $-.30^{\mathrm{c}}$ & $-.34^{\mathrm{c}}$ & $.39^{c}$ & $-.16^{b}$ & $-.15^{b}$ & 1 & & & & & & \\
\hline UP & -.05 & $.10^{\mathrm{a}}$ & $.14^{\mathrm{b}}$ & .06 & $-.15^{b}$ & $-.14^{b}$ & $-.10^{\mathrm{a}}$ & $-.20^{c}$ & $.11^{\mathrm{a}}$ & $-.16^{b}$ & $-.16^{b}$ & $.12^{\mathrm{a}}$ & 1 & & & & & \\
\hline SP & -.03 & -.06 & -.05 & .00 & $.21^{\mathrm{c}}$ & $.15^{\mathrm{b}}$ & $.12^{\mathrm{a}}$ & $.11^{\mathrm{a}}$ & .01 & $.15^{\mathrm{b}}$ & $.18^{\mathrm{c}}$ & -.04 & $-.71^{c}$ & 1 & & & & \\
\hline Int & -.04 & $-.26^{c}$ & .06 & .01 & $.28^{\mathrm{c}}$ & $.32^{\mathrm{c}}$ & $.22^{\mathrm{c}}$ & $.46^{\mathrm{c}}$ & $.31^{\mathrm{c}}$ & $.24^{\mathrm{c}}$ & $.30^{\mathrm{c}}$ & $-.24^{c}$ & $-.10^{\mathrm{a}}$ & .08 & 1 & & & \\
\hline W & $-.11^{\mathrm{a}}$ & $-.24^{c}$ & $.10^{\mathrm{a}}$ & .05 & $.25^{\mathrm{c}}$ & $.23^{\mathrm{c}}$ & $.28^{\mathrm{c}}$ & $.46^{\mathrm{c}}$ & $-.29^{c}$ & $.31^{\mathrm{c}}$ & $.31^{\mathrm{c}}$ & $-.24^{c}$ & $-.15^{b}$ & $.11^{\mathrm{a}}$ & $.55^{\mathrm{c}}$ & 1 & & \\
\hline LS & $-.09^{\mathrm{a}}$ & $-.19^{c}$ & $.13^{\mathrm{b}}$ & .04 & $.24^{\mathrm{c}}$ & $.31^{\mathrm{c}}$ & $.24^{\mathrm{c}}$ & $.38^{\mathrm{c}}$ & $-.25^{\mathrm{c}}$ & $.27^{\mathrm{c}}$ & $.37^{\mathrm{c}}$ & $-.16^{b}$ & $-.11^{\mathrm{a}}$ & $.09^{\mathrm{a}}$ & $.52^{\mathrm{c}}$ & $.48^{\mathrm{c}}$ & 1 & \\
\hline PS & $-.13^{b}$ & $-.16^{b}$ & $.18^{\mathrm{c}}$ & $.16^{\mathrm{b}}$ & $.35^{\mathrm{c}}$ & $.40^{\mathrm{c}}$ & $.36^{\mathrm{c}}$ & $.55^{\mathrm{c}}$ & $-.30^{c}$ & $.39^{\mathrm{c}}$ & $.46^{\mathrm{c}}$ & $-.24^{c}$ & $-.20^{c}$ & $.15^{b}$ & $.49^{c}$ & $.48^{\mathrm{c}}$ & $.55^{\mathrm{c}}$ & 1 \\
\hline$N$ & 1 & 1 & 4 & 6 & 8 & 11 & 4 & 4 & 5 & 5 & 5 & 12 & 6 & 6 & 1 & 4 & 6 & 6 \\
\hline Range & - & - & $4-20$ & $6-30$ & $8-40$ & $0-11$ & $4-20$ & $4-20$ & $5-25$ & $5-25$ & $5-25$ & $12-60$ & $6-42$ & $6-42$ & & $3-21$ & $6-30$ & $6-30$ \\
\hline$M$ & - & - & 6.98 & 10.38 & 22.77 & 3.39 & 10.67 & 12.27 & 18.73 & 8.73 & 9.34 & 41.15 & 29.98 & 18.04 & $\overline{2} .33$ & 6.15 & 8.87 & 10.52 \\
\hline$S D$ & - & - & 2.67 & 4.39 & 6.62 & 2.40 & 5.20 & 6.23 & 7.13 & 5.24 & 5.35 & 8.97 & 8.53 & 8.31 & 1.49 & 3.68 & 2.89 & 4.19 \\
\hline$\alpha$ & - & - & .77 & .89 & .83 & .72 & .83 & .82 & .92 & .87 & .84 & .85 & .91 & .86 & & .83 & .78 & .87 \\
\hline
\end{tabular}

Note. ${ }^{\mathrm{a}} p<.05,{ }^{\mathrm{b}} p<.01,{ }^{\mathrm{c}} p<.001,{ }^{\mathrm{d}}$ Gen $=$ Driver gender; Anx = Anxiety; Dep = Depression; SS = Sensation seeking propensity; RS = Reward sensitivity; Differential association; PA = Personal attitudes; $\mathrm{RA}=$ Risk assessment; $\mathrm{Imi}=$ Imitation; $\mathrm{R}=$ Rewards; $\mathrm{P}=\mathrm{Punishment}$; UP $=\mathrm{Unsafe}$ prototype; SP $=$ Safe prototype; Int $=$ Intentions; $\mathrm{W}=$ Willingness; $\mathrm{LS}=$ Learner speeding; PS = Provisional 1 speeding. _ = not applicable. 
Table 2

Confirmatory factor analysis results for the Akers' SLT and speeding constructs measurement model

\begin{tabular}{|c|c|c|c|c|c|c|c|c|c|c|}
\hline Model & $N$ & $\chi^{2}$ & df & $p$ & CFI & TLI & $\begin{array}{l}\text { RMSEA } \\
{[95 \% \mathrm{CI}]}\end{array}$ & Fit & Revision & $\begin{array}{r}\text { Reliability } \\
(\alpha)\end{array}$ \\
\hline \multirow[t]{2}{*}{ Differential association } & 10 & 540.59 & 34 & $<.001$ & .62 & .50 & $.20[.18, .21]$ & poor & 6 items removed & \\
\hline & $4^{\mathrm{b}}$ & 18.77 & 5 & .002 & .98 & .95 & $.09[.05, .13]$ & good & & $.83^{\mathrm{a}}$ \\
\hline \multirow[t]{2}{*}{ Definitions } & 23 & 2042.37 & 269 & $<.001$ & .71 & .65 & $.13[.13-.14]$ & poor & 12 items removed & \\
\hline & 11 & 226.93 & 59 & $<.001$ & .95 & .93 & $.09[.08, .10]$ & good & divided into subscales & $<.60$ \\
\hline Personal attitudes & $4^{\mathrm{c}}$ & & & & & & & & & $.82^{\mathrm{a}}$ \\
\hline Risk assessment & $5^{\mathrm{c}}$ & & & & & & & & & $.92^{\mathrm{a}}$ \\
\hline \multirow[t]{2}{*}{ Imitation } & 9 & 350.05 & 26 & $<.001$ & .79 & .71 & $.18(.17, .20)$ & poor & 4 items removed & \\
\hline & $5^{\mathrm{d}}$ & 192.01 & 9 & $<.001$ & .84 & .74 & $.23(.20, .26)$ & poor & & $.87^{\mathrm{a}}$ \\
\hline \multirow[t]{2}{*}{ Differential reinforcement } & 17 & 659.43 & 118 & $<.001$ & .76 & .68 & $.11(.10, .12)$ & poor & 12 items removed & \\
\hline & $5^{\mathrm{e}}$ & 35.68 & 5 & $<.001$ & .96 & .91 & $.13(.09, .17)$ & good & renamed 'rewards' & $.84^{\mathrm{a}}$ \\
\hline \multirow[t]{2}{*}{ Reinforcement schedule } & 40 & 2915.69 & 725 & $<.001$ & .64 & .61 & $.09(.09, .09)$ & poor & 28 items removed & \\
\hline & 12 & 126.49 & 44 & $<.001$ & .96 & .95 & $.07(.06, .09)$ & good & renamed 'punishment' & $.85^{\mathrm{a}}$ \\
\hline Learner speeding & 6 & 40.07 & 12 & $<.001$ & .95 & .91 & $.10(.07, .13)$ & good & & $.78^{\mathrm{a}}$ \\
\hline Provisional speeding & 6 & 24.29 & 12 & $=.004$ & .99 & .98 & $.07(.04, .10)$ & good & & $.87^{\mathrm{a}}$ \\
\hline
\end{tabular}

${ }^{a}$ Scales used in hierarchical multiple regression.

${ }^{\mathrm{b}}$ Contained 1 item each exploring peer norms, peer behaviour, priority and intensity dimensions.

${ }^{c}$ Personal attitudes (e.g., 'It's okay to bend the road rules if no one gets hurt'); Risk assessment (e.g., 'If you were to bend the road rules regularly (say twice

a week for a year), what do you think the chances are you would kill someone (including yourself)', 1 no chance, 7 definitely would happen).

${ }^{\mathrm{d}}$ Contained 2 items each for imitation of peers and other young novice drivers, and 1 item for imitation of parents.

${ }^{\mathrm{e}}$ Contained only 'rewards' items - 1 social item, 3 non-social items, and 1 instrumental item.

${ }^{\mathrm{f}}$ Contained only 'punishment' items -5 items for the negative consequences anticipated from friends, 3 items for Police, and 4 items for parents. 
Table 3

Hierarchical multiple regression results for the three analyses predicting self-reported speeding by young novice drivers

\begin{tabular}{|c|c|c|c|c|c|c|c|c|c|}
\hline \multirow[t]{2}{*}{ Variable } & \multicolumn{3}{|c|}{ Step $1^{\mathrm{a}}$} & \multicolumn{3}{|c|}{ Step $2^{b}$} & \multicolumn{3}{|c|}{ Step $3^{\mathrm{c}}$} \\
\hline & $\beta$ & $p$ & $s r^{2}$ & $\beta$ & $p$ & $s r^{2}$ & $\beta$ & $p$ & $s r^{2}$ \\
\hline \multicolumn{10}{|l|}{ Personal characteristics } \\
\hline Gender & -.084 & .081 & & .059 & .177 & & .084 & .032 & .006 \\
\hline Age & -.049 & .302 & & -.069 & .096 & & -.066 & .076 & \\
\hline Car ownership & -.069 & .138 & & -.102 & .012 & .010 & -.083 & .022 & .007 \\
\hline Sensitivity to reward & .263 & $<.001$ & .050 & .159 & .001 & .017 & .091 & .034 & .005 \\
\hline Sensation seeking & .189 & .001 & .026 & .070 & .148 & & .050 & .252 & \\
\hline Depression & .059 & .305 & & .074 & .141 & & .090 & .045 & .005 \\
\hline Anxiety & .079 & .176 & & .056 & .270 & & .025 & .586 & \\
\hline \multicolumn{10}{|c|}{ Akers' Social learning theory variables } \\
\hline Differential association & - & - & & -.005 & .927 & & .008 & .849 & \\
\hline Personal attitudes & - & - & & .335 & $<.001$ & .058 & .218 & $<.001$ & .022 \\
\hline Risk assessment & - & - & & -.096 & .039 & .007 & -.045 & .284 & \\
\hline Imitation & - & - & & .112 & .023 & .008 & .078 & .077 & \\
\hline Rewards & - & - & & .123 & .029 & .008 & .075 & .138 & \\
\hline Punishment & - & - & & -.025 & .577 & & -.010 & .811 & \\
\hline \multicolumn{10}{|c|}{ Gerrard and Gibbons' Prototype/willingness model ${ }^{-}$} \\
\hline Unsafe prototype & - & & & & & & -.087 & .093 & \\
\hline Safe prototype & - & - & & - & - & & -.022 & .662 & \\
\hline Willingness & - & - & & - & - & & .074 & .119 & \\
\hline Intentions & - & - & & - & - & & .092 & .052 & \\
\hline Learner speeding & - & - & & - & - & & .317 & $<.001$ & .063 \\
\hline Adjusted $R^{2}$ & .203 & - & & .411 & - & & $.537^{\mathrm{d}}$ & & 000 \\
\hline$R^{2}$ change & .218 & & & .213 & & & .127 & & \\
\hline
\end{tabular}

Note. Significant predictors are bolded for ease of reference. ${ }^{\mathrm{a}}$ Step $1:{ }^{\mathrm{b}}$ Step $2: F(13,364)=21.27, p<.001 .{ }^{\mathrm{c}}$ Step 3: $F(18,359)=25.28, p<.001 .{ }^{\mathrm{d}}$ A fourth step was undertaken in which the interactions between gender and the SLT and PWM constructs were entered. The step was not significant $(F(15,344)=$ $1.48, p=.11, \Delta \mathrm{R}^{2}=.027$ ) and only one interaction was significant (gender/sensation seeking propensity, $p=.025$ ). 